\title{
What is the Reason for Memory Deterioration during Aging?
}

\author{
Nugzar Aleksidze* \\ Faculty of Exact and Natural Sciences, University GEOMEDI, Georgia \\ ^Corresponding author: Dr. Nugzar Aleksidze, Faculty of Exact and Natural Sciences, University GEOMEDI, Georgia; Email: aleksidze.nugzar@yahoo.com
}

Received: March 16, 2021; Accepted: March 23, 2021; Published: March 26, 2021

\begin{abstract}
The fractional content of water soluble proteins in young and old rats' brain has been studied. It has been established that the water soluble proteins in the brain of old rats are characterized by the excess of high molecular proteins, as compared to the proteins of young ones. We have supposed that the formation of high molecular proteins as a result of the aggregation of disulfide bonds of low molecular proteins should have been due to the determination of number of sulfhydryl groups. As a result of quantitative determination of sulfhydryl groups, the amount of disulfide bonds in the soluble proteins of the brain in old rats appeared to be 50-60\% more, as compared to young rats. It turned out that the activity of NADP-H-dependent disulfide reductase enzyme was about $30-50 \%$ less. The impact of biologically active substances, which activate disulfide reductase on the activity of disulfide reductase and the elaboration of conditional avoidance reflex, was specially studied. It has been established that disulfide reductase activity in the various areas of old rats brain on average increases by 50-60-\% and relatively the development of conditional avoidance reflexes and the memory is improved by $70 \%$.
\end{abstract}

Keywords: Water soluble proteins, Sulfhydryl and disulfide groups, NADP-H-dependent enzyme

It has been established that young rats (4-7 months) for the correct decision of maze tests achieve a maximum criterion after the second test, while the old ones need (25-29 months) more tests, but still do not achieve a maximum criterion. As we have suggested these changes at the level of the brain proteins should have been due to the age of animals. For this purpose a quantitative distribution of water soluble proteins in the brain of young and old rats was studied according to molecular masses. It has been established that the soluble proteins of old rats were distinguished by the content of high molecular mass proteins. We have assumed that this should been have due to disulfide bonds of low molecular proteins, which, in our opinion, caused the aggregation of proteins and memory impairment. Based on the above-said, the number of sulfhydryl groups in the water soluble proteins of the brain in young and old rats was specially studied. After the homogenization of the cortex, white matter of the hemispheres, the cerebellum, the hippocampus and the medulla oblongata, the sulfhydryl groups in water extracts were determined by using the method on the device T-201 [1] developed by us and G. Ellman method [2]. The concentration of protein was measured by O. Lowry et al. method [3] (Table 1).

Proceeding from the above-mentioned, we have got interested in the activity of NADP-H dependent disulfide reductase enzyme in the various brain areas of young and old rats [4-6]. The solution with the following content was used for the incubation: $0.5 \mathrm{ml}$ buffer of Tris- $\mathrm{HCl}$ (pH 7.4, $0.5 \mathrm{ml}$ DTNB (50 mM, $0.5 \mathrm{ml} \mathrm{NADP}-\mathrm{H}(100 \mathrm{mM})$ and $0.5 \mathrm{ml}$; protein solution ( $1 \mathrm{mg} / \mathrm{ml}$ ) [6]. As seen from the Table 2 , the activity of HADP-H-dependent disulfide reductase is decreased about by $30-50 \%$
Table 1: Quantitative distribution of sulfhydryl and disulfhydryl groups in water soluble proteins in brain specific structures of young and old rats $\left(10^{-6} / 100 / \mathrm{mg}\right.$ protein).

\begin{tabular}{|l|c|c|c|c|}
\hline Brain structures & Young rats & Old rats & $\begin{array}{c}\text { Young rats } \\
\text {-SH- }\end{array}$ & $\begin{array}{c}\text { Old rats } \\
\text {-S-S- }\end{array}$ \\
\hline The brain cortex & 0.622 & 0.500 & 0.06 & 0.08 \\
\hline White matter & 0.670 & 0.454 & 0.07 & 0.15 \\
\hline The cerebellum & 0.680 & 0.526 & 0.06 & 0.12 \\
\hline Medulla oblongata & 0.793 & 0.478 & 0.08 & 0.14 \\
\hline The hippocampus & 0.543 & 0.352 & 0.05 & 0.12 \\
\hline
\end{tabular}

Table 2: The activity of NADP-H-dependent disulfide reductase of young and old rats in conventional units.

\begin{tabular}{|l|c|c|}
\hline Brain structures & Young rats & Old rats \\
\hline Cortex of hemispheres & $0.125 \pm 0.008$ & $0.060 \pm 0.003,<0.001$ \\
\hline White matter & $0.104 \pm 0.013$ & $0.058 \pm 0.003,<0.003$ \\
\hline The cerebellum & $0.124 \pm 0.009$ & $0.064 \pm 0.004<0.001$ \\
\hline Medulla oblongata & $0.088 \pm 0.004$ & $0.062 \pm 0.003,<0.01$ \\
\hline The hippocampus & $0.104 \pm 0.005$ & $0.087 \pm 0.004,<0.01$ \\
\hline
\end{tabular}

in the brain of old rats. Most researchers engaged in the study of reasons for the memory impairment attribute such changes in the functional activity of the brain to gene mutations and perhaps it is probable that the decrease in the activity of NADP-H-dependent disulfide reductase must be exactly the result of gene mutations at the level of nerve cells [7].

Based on the above-mentioned, we started searching for the biologically active substances which activated the activity of disulfide reductase enzyme. The impact of the injection of biologically 
active substances into the ventricles of young and old rats' brain on the activity of NADP-H-dependent disulfide reductase and the elaboration of conditional avoidance reflex was specially studied [8]. In the hemispheric cortex, the white matter, medulla oblongata and the hippocampus of the brain the number of sulfhydryl groups relatively increased by $30 \%, 29 \%$ and $37 \%$ only in old rats, as compared with the control, while under the influence of hydrocortisone the number of sulfhydryl groups increased by $45 \%$. Relatively, the elaboration of conditional avoidance reflex and the memory was improved by $70 \%$ $[6,8]$. Based on the mentioned, we think that for the prevention it is desirable to take foods rich in amino acids containing sulfhydryl groups, cysteine and methionine: pork, salmon fillet, milk, cheese, chicken and turkey meat, sunflower, nuts, etc.

Noteworthy is the fact that in Nigeria, where the cases of Alzheimer's disease are rare, the substances, inhibiting the activity of acetylcholinesterase in the vegetables have been discovered, at the affinity of which the activity of the enzyme is inhibited by the extract of Spondia mombin root bark - by $83.94 \%$, the extract of Callophinophyllum inoophyllum root bark - by $58.52 \%$, the extract of C. jagus leaves - by $74.25 \%$, the extract of Combreteeum molle leaves and stem, relatively, by 90.42 and $88.13 \%$ [9]. It should also be mentioned that in conditions of memory impairment, the aged people were often offered to take the drugs, activating the cholinergic system. It is likely that at the expense of acetylcholinesterase activity inhibition, as a result of the accumulation of an exciting neurotransmitter - acetylcholine, the neurons and neuronal ensembles remain to be active for a long time and enhance the stabilization of memory engram. For the prevention it is necessary to activate the neurons and neuronal ensembles by reading, listening to classical music, playing chess, puzzle solution, learning foreign languages, physical trainings and active public activities [10]. Otherwise, while leaving neuronal ensembles in the state of hypokinesia for a long time a quantitative reduction of the number of synapses decreases, neuron death takes place and, as a result the memory is impaired [11].

\section{Conclusion}

Proceeding from the above data, one of the possibilities of memory improvement of aged people should be considered the recovery of disulfide bonds by means of those biologically active substances, by which the activation of NADP-H-dependent disulfhydreductase enzyme, the recovery of disulfide bonds excess and, in our opinion in the perspective, the memory improvement.

\section{References}

1. Aleksidze N., Koshoridze N (1980) Determination of sulfhydryl groups by laboratory titrator T-201. Bull Experimental Biology and Medicine 89: 85-87.

2. Ellman GL, Kcourtney YD, Andres V, Feather-Stone RM (1961) Rapid colorimetric determination of acetylcholinesterase activity. Biochem Pharmacol 7: 88-95. [crossref]

3. Lowry OH, Rosenbrough NJ, Farr AL, Randall RJ (1951) Protein measurement with the Folin Phenol Reagent. J Biol Chem 193: 265-275. [crossref]

4. Tietze T (1970) Arch Biochem Biophys 138: 112-114.

5. Dringen R, Gutterer JM (2002) Glutathione reductase from bovine brain. Methods Enzymol 348: 281-288. [crossref]

6. Aleksidze N, Koshoridze N (1984) Changes in disulfide reductase activity of rat brain at aging. Neirokhimia 3: 51-53 (in Russian).

7. Aleman A (2018) Brain on pensions: what happens to the brain during aging? 450.

8. Aleksidze N., Koshoridze N (1983) The impact of adrenaline and hydrocortisone on disulfide reductase activity of the brain. Neirokhimia 2: 199-204 (in Russian).

9. Elufioye TO, Obuotor EM, Sennuga AT, Agbedahunsi JM, Adesanya SA (2010) Acetylcholinesterase and butyrylcholinesterase inhibitory activity of some selected Nigerian medicinal plants. Rev Bras Farmacogn 20: 45-50.

10. Aleksidze N (2014) The basics of psychobiology. The Publishng House of Georgian National Academy of Sciences 223.

11. Butz M, Ooyen A van (2013) A Simple rule for dendritic spine and axonal bouton formation can account for cortical reorganization after focal retinal lesions. PLoS Computational Biology 9: 1371-1380. [crossref] 